\title{
Wave and plasma measurements and GPS diagnostics of the main ionospheric trough as a hybrid method used for Space Weather purposes
}

\author{
H. Rothkaehl ${ }^{1}$, A. Krakowski ${ }^{2}$, I. Stanislawska ${ }^{1}$, J. Błęcki ${ }^{1}$, M. Parrot ${ }^{3}$, J.-J. Berthelier ${ }^{4}$, and J.-P. Lebreton ${ }^{5}$ \\ ${ }^{1}$ Space Research Centre PAS 00-716 Warsaw, Bartycka 18A, Poland \\ ${ }^{2}$ University of Warmia and Mazury in Olsztyn, Poland \\ ${ }^{3}$ LPCE/CNRS 3A, avenue de la Recherche Scientifique 45071 Orléans cedex 02, France \\ ${ }^{4}$ CETP/ Observatoire de Saint-Maur 4, avenue de Neptune94107 Saint-Maur-des-Fossés Cedex, France \\ ${ }^{5}$ RSSD/ESTEC/ESA Postbus 2992200 AG Noordwijk, The Netherlands
}

Received: 1 February 2007 - Revised: 15 November 2007 - Accepted: 13 February 2008 - Published: 26 February 2008

\begin{abstract}
The region of the main ionospheric trough is a unique region of the ionosphere, where different types of waves and instabilities can be generated. This region of the ionosphere acts like a lens, focusing a variety of indicators from the equator of plasmapause and local ionospheric plasma. This paper reports the results of monitoring the midlatitude trough structure, dynamics and wave activity. For these purposes, the data gathered by the currently-operating DEMETER satellite and past diagnostics located on IK-19, Apex, and MAGION-3 spacecraft, as well as TEC measurements were used. A global-time varying picture of the ionospheric trough was reconstructed using the sequence of wave spectra registered and plasma measurements in the topside ionosphere. The authors present the wave activity from ULF frequency band to the HF frequency detected inside the trough region and discuss its properties during geomagnetic disturbances. It is thought that broadband emissions are correlated with low frequency radiation, which is excited by the wave-particle interaction in the equatorial plasmapause and moves to the ionosphere along the geomagnetic field line. In the ionosphere, the suprathermal electrons can interact with these electrostatic waves and excite electron acoustic waves or HF longitudinal plasma waves.
\end{abstract}

Furthermore, the electron density trough can provide useful data on the magnetosphere ionosphere dynamics and morphology and, in consequence, can be used for Space Weather purposes.

Keywords. Ionosphere (Ionosphere-magnetosphere interactions; Mid-latitude ionosphere; Plasma waves and instabilities)

Correspondence to: H. Rothkaehl

(hrot@cbk.waw.pl)

\section{Introduction}

The mid-latitude trough region is one of most important regions in the ionosphere, particularly as a deeper understanding of the physical processes occurring in this region can enhance knowledge about ionosphere-magnetosphere coupling. This boundary layer of the near-Earth environment is a unique region, where local and remote indicators play important roles. Despite the long history of observations and theoretical approach of the main ionospheric trough, knowledge is still lacking. The main ionospheric trough is a night-side phenomena, this depletion in electron density is very often correlated with an inverse relation of electron temperature. The poleward edge of main ionospheric trough is steeper than the equatorward wall of the trough, particularly during quiet geomagnetic conditions. However, very limited registration have observed the three-dimensional irregular structure of the main ionospheric trough (Mendillo, 1977; Vo and Foster, 2001).

The main ionospheric trough features is a very dynamic structure. It is a well-known fact that the trough structure moves to lower latitudes both with an increasing level of geomagnetic activity as well as with an increasing time interval from the local magnetic midnight. A review of the observation data and proposed physical and empirical models shows the complexity of the morphology and dynamics of the main ionospheric trough occurring in different conditions of the near-Earth environment. The main ionospheric trough forming mechanism can be the result of horizontal convection and field-aligned plasma transport, changes in the electric and magnetic fields, precipitation of electrons and protons, interaction of ionospheric plasma with neutral components and recombination and ionisation processes occurring in the ionosphere and inner magnetosphere. (Moffett and Quegan, 1983; Rodger et al., 1992; Lemaire, 2001; Tulunay et al.,

Published by Copernicus Publications on behalf of the European Geosciences Union. 
2003; Nilsson et al., 2005). In order to improve the models of morphology and the dynamics of the main ionopsheric trough, it is necessary to estimate the ratio between acceleration and loss processes in the ionosphere and the inner magnetosphere plasma. Moreover, the wave-particle interactions in the region near the plasmapause have a significant influence on space plasma properties at ionospheric altitudes (Reynolds et al., 2001).

Since the first low-orbiting satellites were located in nearEarth orbits, many satellite techniques have been used to monitor the properties and dynamics of ionospheric trough features (Muldrew, 1965; Tulunay and Grebowsky, 1978; Rodger et al., 1992). Moreover, a series of ground-based campaigns using the ionosondes network and radar facilities have been performed (Dudney et al., 1983; Evans et al., 1983; Foster et al., 1988). Also three-dimensional imaging of the main ionospheric trough using multiple radars and satellite registrations was presented by Hedin at al. (2000). Recently, by using tomographic reconstruction of ionopsheric features and GPS measurements, some analyses of the main ionospheric trough were done (Pryse et al., 1998; Blagoveshchensky et al., 2005; Yizengaw and Moldwin, 2005). Since the first trough features registration, a number of different empirical equations which express the position of the main ionospheric trough in functions of local time and geomagnetic indexes were elaborated (Rycroft and Burnell, 1970; Tulunay, 1972; Werner and Proelss, 1997; Bradley et al., 1998; Karpatchev et al., 2003). Nevertheless, all of these models are incomplete, due to the limitation of temporal and spatial measurement resolution. Even the Karpatchev models include the parameterisation of longitude, altitude, season, local time and solar and magnetic activity, but are limited due to the observation methods. As satellite in situ techniques permit registration of physical phenomena at a defined point in space and time only, the registered grid databases are not complete. On other hand, ground-based techniques can only provide information about the time evolution of an observed structure at a defined single station (observation point). As a consequence of the short period of space experiments, the presented empirical models are only adequate for selected periods during different solar cycles. In addition, a number of different numerical simulations by Knudsen et al. (1977), Sojka et al. (1990), Fuller-Rowell et al. (1991), Rodger et al. (1992) are presented. They confirm that the current understanding of the physical processes operating in the midand high-latitude ionosphere is correct. However, the individual mechanisms of some variations are not well defined.

The majority of experimental data gathered by satellites in the topside ionosphere, as well as by ground-based instruments, concern registration of such the plasma parameters as the density and temperature of both electrons and ions. Only a few investigations have been carried out using in situ wave measurements (Rothkaehl et al., 1997).

The mid-latitude electron density trough observed in the topside ionosphere has been shown to be the near-Earth signature of the magnetospheric plasmapause, and thus its behaviour can provide useful information about the magnetosphere dynamics since its existence is dependent on magnetospherically-induced motions. (Grebowsky et al., 1976; Queqan et al., 1982; Jiricek et al., 1996; Rothkaehl et al., 1997). Yizengaw et al. (2005), using ground-based GPS TEC data and IMAGE EUV images of the plasmasphere, have compared the locations of the plasmapause and mid-latitude trough on a global scale. All authors conclude that plasmapause position has a close link with the midlatitude trough at both the $\mathrm{F}$ layer and the topside ionosphere. Slight differences in the positions of these two structures have been observed, particularly during geomagnetic storms (Rothkaehl et al., 1997).

The aim of this paper is to present the wave activity from the ULF frequency band to the HF frequency detected inside the trough region and discuss their properties during geomagnetic disturbances. The previously carried out investigations based on the data collected by the low orbiting MAGION-3 satellite showed a remarkable intensification of broadband emissions in the VLF and HF frequencies during a geomagnetic storm inside the trough region (Rothkaehl et al., 1997). The current in situ wave and particle measurements performed on the DEMETER satellite and on the GPS diagnostics provide new challenges to describe the dynamics and detailed structures of the main ionopsheric trough. These analyses also give new data on wave particle interaction in the topside ionosphere and could be very helpful for improving the understanding of the ionosphere-magnetosphere coupling processes. The proposed mechanism of intensification of broad band VLF and HF frequency emissions during strong geomagnetic disturbances could also show the links between the topside ionosphere and the remote plasmapause region.

\section{Diagnostics techniques and instrumentations}

The complexity of describing the topology and dynamics of ionospheric trough position and evolution, particularly during strong geomagnetic disturbances, is not trivial. Particularly during varying geomagnetic activity, it is very hard do determine the border of the ionospheric trough. The criteria which were used for examining the morphology and dynamics of the ionospheric trough were based on experience from previously performed space experiments in the top-side ionosphere. To determine the border of the ionospheric trough, plasma particle measurements were used such as the Langmuir probe for diagnosing electron and ion density and temperature. Furthermore, for this analysis wave diagnostics were employed across the entire frequency range, from ULF thru VLF up to the HF frequency range. In order to obtain the global distribution of electron plasma density, a map of TEC measurements was constructed. 
The current study used the results from past observations registered on board the MAGION-3 satellite, data gathered on the currently-operated satellite DEMETER and GPS observations collected from the IGS permanent GPS network (EPN).

The MAGION-3 satellite was launched in December 1989 with an initial perigee of $430 \mathrm{~km}$, an apogee of $3,100 \mathrm{~km}$ and an inclination of 82.5, as a part of the APEX project. The ELF-VLF wave experiment was operated in the $10 \mathrm{~Hz}-$ $60 \mathrm{kHz}$ frequency range with a $120 \mathrm{~dB}$ dynamic range. A PRS-3 synthesizer radiospectrometer was operated in the $0.1-10 \mathrm{MHz}$ frequency band with an effective bandwidth of $15 \mathrm{kHz}$. The individual spectra had a time resolution from $0.1-1 \mathrm{~s}$ and a $80 \mathrm{~dB}$ sensitivity The Langmuir probe onboard the subsatellite MAGION-3 worked in the sweep adaptive voltage regime and performed in-situ diagnosis of the cold thermal plasma in the topside ionosphere. A highenergy charged particle spectrometer DOK-S located on the MAGION-3 satellite diagnosed populations of electrons in the energy range of $25 \mathrm{keV}-600 \mathrm{keV}$ and the population of ions in the energy range of $20 \mathrm{keV}-1.3 \mathrm{MeV}$.

DEMETER was launched on 29 June 2004 with an initial altitude of about $710 \mathrm{~km}$ and an inclination of $98.3^{\circ}$ (Parrot, 2002). In order to study the response to the seismic activity in the ionosphere and to monitor the electromagnetic Earth environment, the DEMETER spacecraft was equipped with instruments to measure the six components of the electromagnetic wave field in the wide-frequency band and for determining plasma parameters such as ion density, electron density and temperature and electron energy fluxes. The scientific payload was composed of five instruments: ICE, three electric sensors from DC up to $3.5 \mathrm{MHz}$ (Berthelier et al., 2006), IMSC, three magnetic sensors from a few $\mathrm{Hz}$ up to $18 \mathrm{kHz}$, IAP, an ion analyzer, IDP, an energy particle detector (Sauvaud et al., 2006), ISL and a Langmuir probe (Lebreton et al., 2006).

GPS observations collected from the IGS permanent GPS network (EPN) were used as the source of TEC data. A single-site algorithm was used for TEC calculations over a single station (Baran et al., 1997; Krankowski et al., 2005a, b). GPS observations collected by IGS were used to create TEC maps. More than 100 stations from Europe and North America were included in the analysis (Krankowski et al., 2004). The dense world-wide GPS permanent network provided high TEC resolution (Hernandez-Pajares et al., 1997).

While estimating TEC from GPS observations, the ionosphere was approximated by a spherical shell at a fixed height of $400 \mathrm{~km}$ above the Earth's surface. A geometric factor was used to convert the slanted TEC into a vertical one. To reduce the influence of horizontal gradients, the lowest elevation angle considered in the GPS data was 200. High-precision phase measurements were used while processing. The phase ambiguities were removed by fitting phase measurements to the code data collected along an individual satellite pass. After pre-processing, the phase measurements contained an in- strumental bias only (Baran et al., 1997). The biases were determined for each station using GPS measurements of all satellite passes over a given site in a 24 -h period. The diurnal variations of TEC over a site and the biases for all satellites were estimated simultaneously. At all stations, before the technique was run, the instrumental biases were removed in all satellite passes. Using this procedure, an absolute line of sight TEC for all satellite-receiver paths was calculated.

In order to obtain the spatial and temporal variation of TEC and to create TEC maps, the measurements were fitted to a spherical harmonic expansion in a geographic latitude $(\Phi)$ and longitude $(\Theta)$. The spherical harmonic expansion was truncated to the order and degree of 16 . The accuracy of TEC maps depends on spatial gaps in TEC data (Mannucci et al., 1998). The large number of GPS stations in Europe and North America provide good coverage for GPS data and enable high-accuracy TEC maps with errors at a level of 0.52 TECU. The coverage is a very adequate shell and yields a reasonable surface harmonic fit, providing TEC maps with a spatial resolution of $100-300 \mathrm{~km}$ and a time resolution of 5 min.

\section{The manifestation of the main ionospheric trough during a geomagnetic storm}

\subsection{Growth phase of geomagnetic storm}

During increased geomagnetic activity, the border of the auroral oval expands to the lower latitudes and enhances the convection of the electrical field. Consequently, there is an increase of recombination processes observed in the subauroral regions (Rodger et al., 1992). In the subauroral region, the intensification of electrical field-aligned currents FAC (Foster et al., 1988) and precipitation of energetic energy particles is observed. Moreover, subauroral ion drift (SAID) events associated with an ionospheric trough, defined as westward convection, are very often registered (Spiro et al., 1979; Foster and Vo, 2002).

Previous observations performed by the low orbiting satellites MAGION-3 and APEX showed that during increased geomagnetic activity, there is a pronounced increase of depletion in plasma density in the main ionospheric trough, a growth of electron temperature and an excitation of wave activity in the VLF and HF frequency range regions (Bradley et al., 1997; Rothkaehl et al., 2000).

The ground-based whistler diagnostics and in situ measurements showed that the plasmapause usually occurs on the same field line, or slightly above, the equatorward edge of the main ionospheric trough (Grebowsky et al., 1976; Queqan et al., 1982; Smith et al., 1987; Yizengaw et al., 2003).

The cross-tail electric fields play a very important role in forming the plasmapause and consequently the trough structure in the ionosphere. The observed differences of localization in L shells of these two features can occur during 
Dst

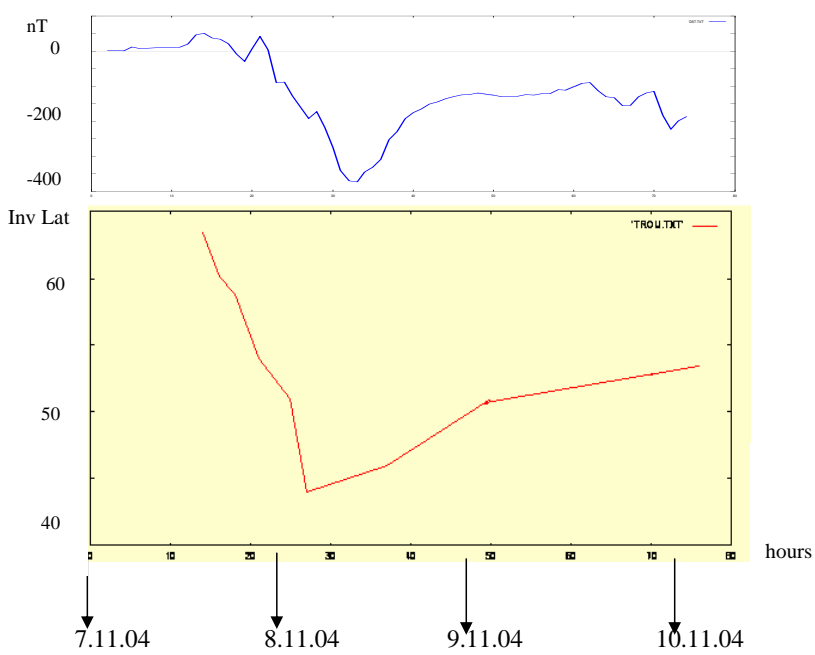

Fig. 1. Evolution of position northward ionospheric trough during geomagnetic storm on 7-10 November 2004 (bottom panel) determined by data gathered on board of DEMETER satellite (for the same 20:00-21:00 MLT), bottom panel. Upper panel represents the evolution of $D_{s t}$ index.

a strong magnetic storm and just after (Rothkaehl et al., 1997). The delay between the position of projection the plasmapause at the ionospheric altitude and the position of the through minimum determined by in situ measurements of the MAGION-3 satellite position was detected. For a better understanding of the role of global processes within the ionosphere, the movement of the northward edge of main ionospheric trough along the geographic latitude during strong geomagnetic storm on November 2004 was plotted in Fig. 1. It is evident that during the recovery phase, the trough structure came back slower to the higher latitude than was detected in the growth phase. A similar behavior of the plasmapause dynamic was detected by Jiricek et al. (1996) and Rothkaehl et al. (1997) using data gathered on a MAGION3 satellite. Thus, the value of any geomagnetic activity index incorporated in an empirical model used for describing the movement of ionospheric trough features could be modified by factors related to the appropriate geomagnetic storm phase.

When geomagnetic activity started to increase, increases in electron temperature and wave activity were registered. Later on, a deepening of plasma depletion and ionospheric trough feature movement along the geomagnetic latitude towards the equator was observed. At that moment, a different type of physical process with different typical scales (from minutes up to milliseconds) occurred in the ionosphere and in the inner magnetosphere. The main ionospheric trough can be affected by horizontal convection, field aligned plasma transport, changes in electrical and magnetic fields, precipitation of electrons, interaction of ionospheric plasma with neutral components and recombination and ionisation processes and particle wave interaction occurring in the ionosphere and inner magnetosphere. In consequence, different types of ionospheric trough shapes were observed. During the increased geomagnetic activity on 7 November 2004, very rapid movement of the ionospheric trough along the geomagnetic latitude was detected (Fig. 2). In consequence, a double trough structure (irregular structures with two local minimums) was registered. The fine structure of enhanced electron temperature was also clearly visible. During quite quiet geomagnetic conditions, the northward edge of ionospheric trough is the border of energetic particle precipitation, but in this case, a beam of hot electrons with energy levels of up to $2.5 \mathrm{MeV}$ inside the trough region was also detected. The peak beam density was observed for energy around a few $\mathrm{keV}$. As previously observed during the growth phase of a magnetic storm, the MAGION-3 satellite registered a significant enhancement of emissions in the VLF frequency range. A ground-based investigation done by the Milistone Hill radar facility showed enhancements of the ion acoustic mode in the mid-latitude trough region correlated with intensification of the field-aligned current(Foster et al., 1988). Usually, an increase in broadband emissions from the low to high frequency band can be observed, but in this case a significant increase in LHR lower hybrid resonances was also detected. The data registered by the DEMETER satellite recorded an intensification of broadband emissions in ULF and LF up to the cutoff in the local proton gyrofrequency. In the top-side ionosphere, at an altitude of around $700 \mathrm{~km}$, the properties of ionospheric plasma can be effected by the domination of dense plasma (i.e. where the electron plasma frequency is greater than the electron cyclotron frequency). For high frequency emissions, the ratio of electron plasma frequency to the electron gyrofrequency is a key parameter for exciting a different type of wave activity. Exceptionally, inside the trough region the electron density sometimes drops rapidly and local electron plasma frequency can then be lower than the electron gyrofrequecy. In consequence, this plasma condition can promote the generation of upper hybrid resonances (UHR). The wave and particle diagnostics located on the low orbiting satellite can give us very precisely diagnostics, although very limited in time and space. Until there is one point in situ or with ground base measurements, it will not be possible to describe such a rapid time evolution and three-dimensional space of mid-latitude trough structures or to distinguish between time and spatial structures.

In order to produce an average map of near-Earth space conditions, the TEC measurements gathered on several spacecraft were used. Next, one hour maps were constructed for the defined region. Figure 2 shows clear trough features and red stars mark the position of the ionospheric trough determined using the plasma measurements performed by the DEMETER satellite. The difference of the position of the mid-latitude trough obtained in situ at $700 \mathrm{~km}$ and by the 


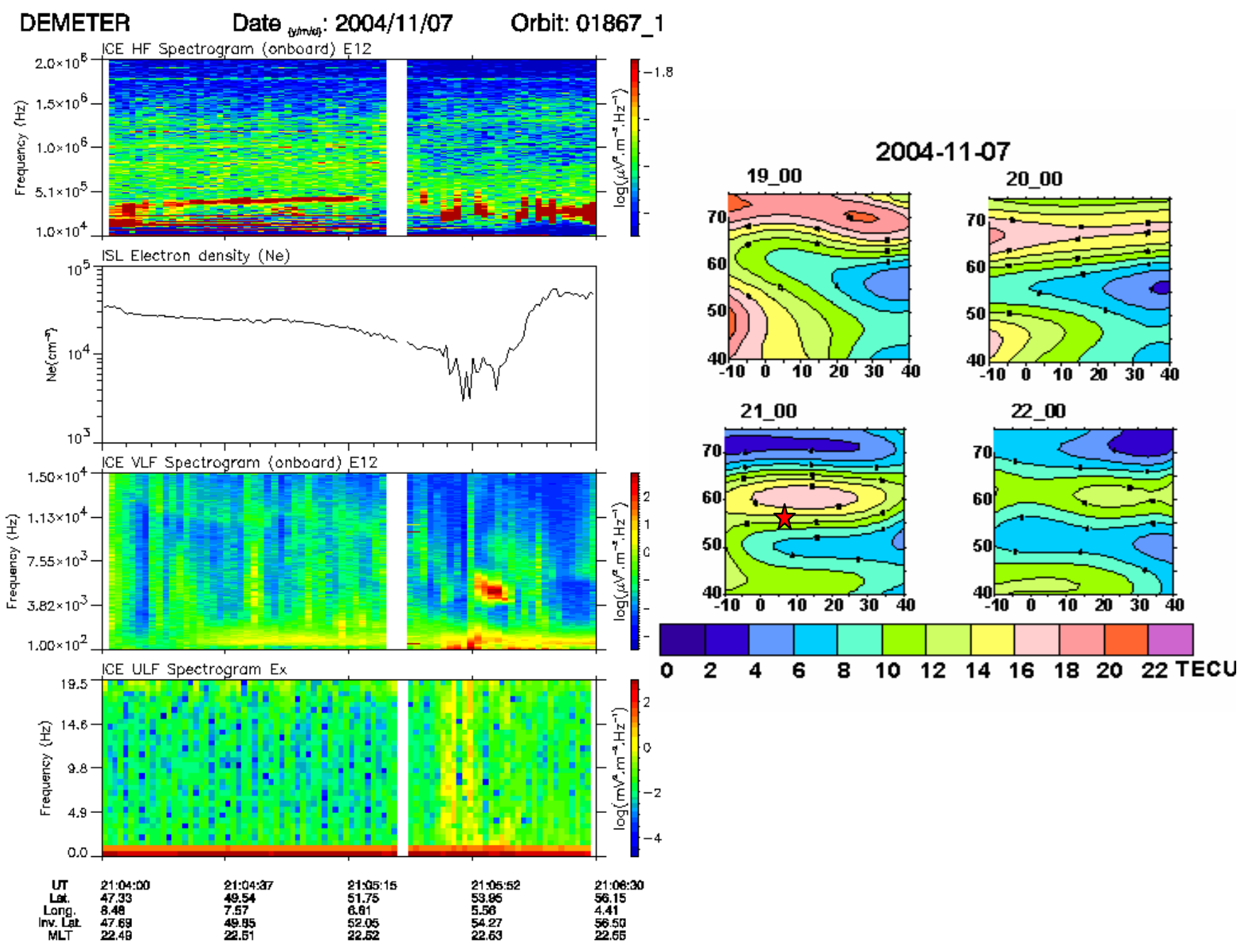

Fig. 2. The sequence of wave and plasma measurements registered on board of DEMETER satellite on 7 November 2004 during growth phase of geomagnetic storm left panel, differential TEC maps over Europe for 7 November 2004 right panel. Red stars marks the position of trough determined form in situ measurements.

TEC measurements is clear. The changes of TEC value are dominated by the changes in $\mathrm{F} 2$ region but the lower part of the ionosphere can also contribute. On the other hand, TEC maps can mainly reflect the general behaviour of electron density in the near-Earth environment, so during such sudden and strong rebuilding of ionospheric and magnetospheric structures, this technique is not sufficient. Thus, plasma and wave in situ diagnostics and average general TEC maps can give a more realistic scenario of evolution in the near-Earth environment during geomagnetic storms.

\subsection{Main phase}

As is usually observed, the main ionospheric trough moved to a lower latitude during the main phase of a geomagnetic storm. The very complex process of rebuilding the topside ionosphere can give rise to broadening the width of the iono- spheric trough and in consequence, the equatorward edge of the trough was steepened. The intensification of field-aligned currents and the precipitating fluxes of energetic particles caused an intensification of wave activity.

At the equator of the plasmapause, the heating process of heating the magnetospheric plasma is started. However, SAID have been associated with disturbed conditions and specifically with the substorm recovery phase (Anderson et al., 1993). In consequence, enhanced electromagnetic ion cyclotron EMIC and Alfvén waves can observed at the plasmapause equator (Fraser and Nguyen 2001). At ionospheric heights, the heating process starts with a delay to the ring current switch of about $10 \mathrm{~min}$ for electrons and $1 \mathrm{~h}$ for ions (Gorbatchev et al., 1992).

A detailed examination performed by the MAGION-3 satellite showed the similar properties of trough signatures during the main phase of a geomagnetic storm (Rothkaehl 

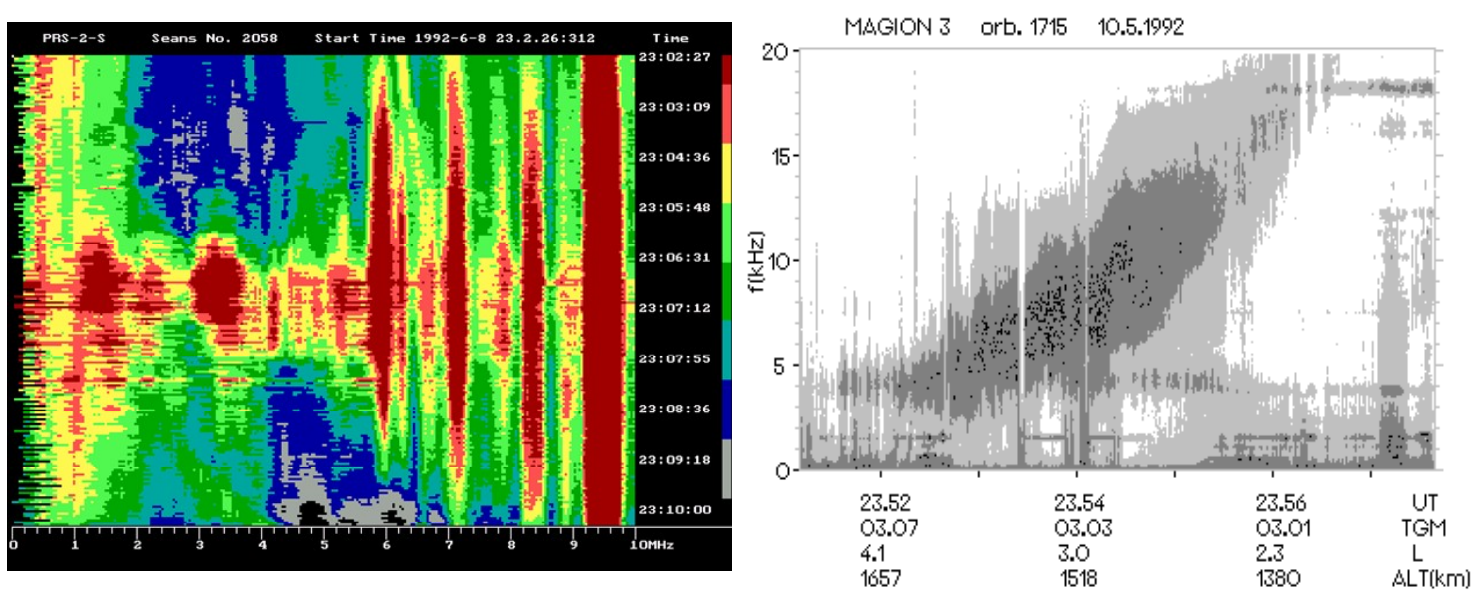

Fig. 3. The sequence of dynamic HF spectra detected over ionospheric trough along orbit 2058 during the main phase of the storm on board of MAGION-3 satellite. The enhancement of the broad band emission has been detected at altitude $500 \mathrm{~km}$, left panel, the spectrogram of VLF emissions detected over the trough region along orbit 1715 on 10 May 1992 during main phase of geomagnetic storm. The plasmapause position shrank to $L=2.1$ (right panel).

et al., 1997). An intensification of broadband HF and VLF waves was also registered at the ionospheric height (Fig. 3). An examination of $\mathrm{HF}$ radio emissions indicates the enhancement of radiation at frequencies larger than the local upper hybrid limit. This broadband emission is mainly detected very close to the plasmapause, inside the plasmasphere, but it also exists inside the trough up to the auroral oval. This type of emission is mainly correlated with low frequency radiation, which is excited by the wave-particle interaction in the equatorial plasmapause and moves to the ionosphere along the geomagnetic field line. The field-aligned current in the ionosphere can create ion sound turbulence (Khazanov et al., 1994). In the topside ionosphere, a supra-thermal electron can interact with electrostatic waves and excite electron acoustic waves or HF longitudinal plasma waves. The current investigation using a DEMETER database shows that during the main phase of a geomagnetic storm, an intensification of broadband emission in the VLF frequency band and in the LF frequency band up to the local proton gyrofrequency was detected (Fig. 4). As in the growth phase, a disparity between the position of the trough determined by in situ measurements and by GPS diagnostics was found.

\subsection{Recovery phase}

During the recovery phase of the geomagnetic storm, the trough structure changed as the plasmapause again moved to the higher latitudes, but not as rapidly as in the growth phase.

The detail investigations found, once more, an irregular (multi-trough features) structure of the ionospheric trough shape at that time. The wave diagnostics located on the DEMETER satellite indicated a slight (not as pronounced as during the growth phase or during the main phase of a geomagnetic storm) enhancement of wave intensity in the VLF frequency band and intensification of emissions from ULF up to local proton gyrofrequency.

Inside the plasmasphere, close to the equatoward edge of ionospheric trough (in the same L-shell where the ionosheric trough was located during the main phase of the geomagnetic storm) an intensification of emissions in the VLF frequency range was detected. These "fossil emissions" are a very good indicator of a turbulent plasma region correlated with physical processes occurring at the near equator of the plasmapause region as well as at the ionospheric latitude (Fig. 5). The enhancement of electron temperature in this region at ionosphere altitude was also registered. This confirmed the results of previous examinations using data gathered during disturbed geomagnetic conditions by MAGION-3 (Jiricek et al., 1996; Rothkaehl et al., 1997). However, previous observations carried out by a MAGION -3 satellite also revealed the existence of "fossil emissions". The authors concluded that such broadband emissions in the high frequency band registered for frequencies larger then local plasma frequency could have been generated by the scattering of electrons on ion sounds or Langmuir turbulence.

In order to describe the general behavior of the topside ionosphere, global TEC maps were constructed. But in this case, the position of ionospheric trough as determined by plasma and particle diagnostics by the DEMETER satellite corresponds to the position of the ionospheric trough determined by TEC diagnostics

\section{Conclusion}

To develop a quantitative model of the interaction between the inner magnetosphere and topside ionosphere region applicable in the Space Weather program, it is necessary to 


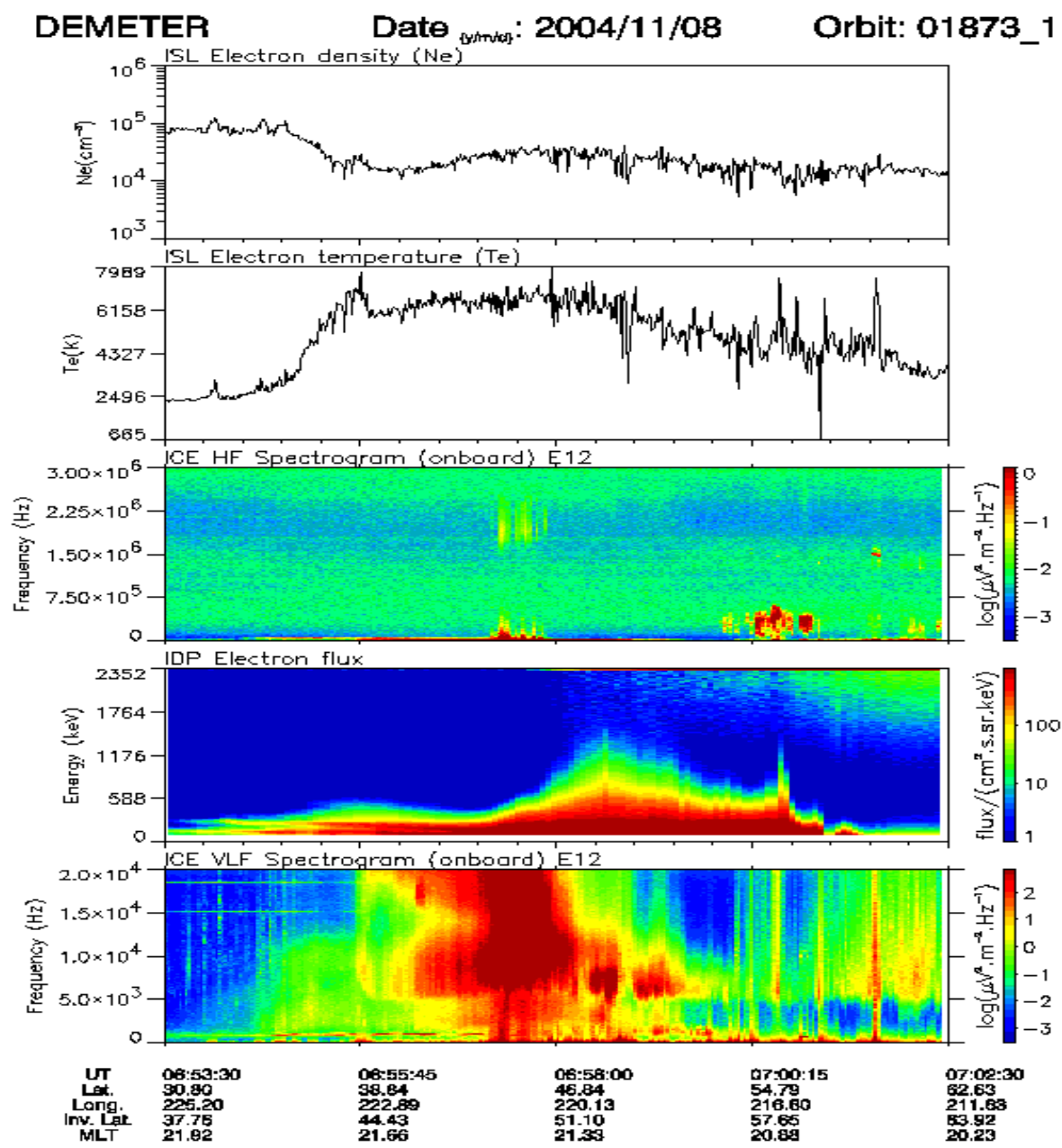

Fig. 4. The sequence of wave and plasma measurements registered on board of DEMETER satellite on 8 November 2004 during main phase of geomagnetic storm.

consider in situ plasma, wave diagnostics and the ground network of different diagnostic instruments and TEC data derived from the commercial GPS network. Despite the long history of such studies performed by ground-based techniques and space-borne instruments, the physical properties of the main ionospheric trough are not well understood. Horizontal convection, field-aligned plasma transport, changes in the electric and magnetic fields, precipitation of electrons, interaction of ionospheric plasma with neutral components and recombination and ionisation processes and wave particle interactions in the ionosphere and inner magnetosphere are responsible for main ionospheric trough formation. In consequence, a description of the morphology and dynamics of the main ionospheric trough seems to be very complex, therefore, the scope of the current studies should cover a wide range of physical processes in space.

Currently, a general description of the dynamics of trough features is well-known, but a deeper understanding of ionosphere magnetosphere coupling is needed. In particular, un- derstanding the wave particle interaction in the main iononpheric trough region and close to the plasmapause would improve the understanding of physical processes in the nearEarth environment.

On the basis of case studies of selected geomagnetic storms, the typical morphology of the middle-latitude trough and wave activity inside the trough is known. The studies were based on the data gathered by low orbiting spacecraft such as IK-19, MAGION-3 and DEMETER.

In order for the physical processes responsible for reconstructing the top-side ionosphere to be processed with different time scales in different regions (particularly in the $f o \mathrm{~F} 2$ layers and at the equator of plasmapause) the irregular and double-structural shape of the ionospheric trough was detected during strong and rapid changes in geomagnetic activity.

Moreover, a hybrid method based on wave diagnostics across the whole frequency band, was elaborated using electron and density temperature measurements. Particularly 


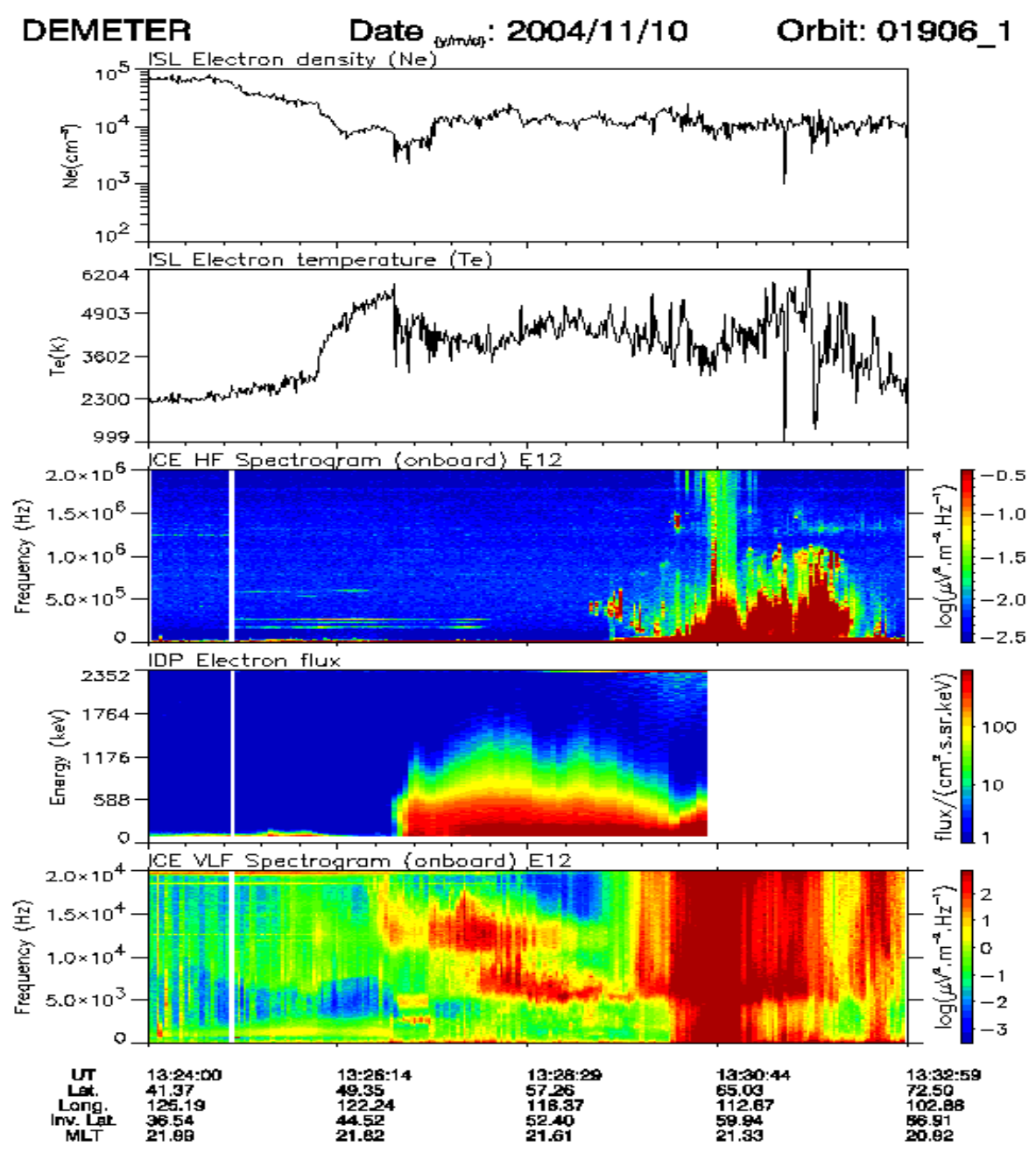

Fig. 5. The sequence of wave and plasma measurements registered on board of Demeter satellite on 9 November 2004 during recovery phase geomagnetic storm.

during changes in geomagnetic activity, determination of the trough position is not possible using only one type of diagnostic. This method was applied for determining the trough minimum position, poleward edge and equatorward edge of the main ionospheric trough. The global maps constructed using the TEC data gathered by the GPS network was used for validation in situ measurements and for describing the general property and tendencies in the near-Earth plasma environment. The above-described technique will be applied to construct an empirical formulae which should be very challenging for forecasting purposes in the Space Weather program. The constructed models can provide data on the position of the main ionospheric trough and also give data on the topology of the remote plasmapause region.

The study found that during strong geomagnetic disturbances, increases in broadband wave emission beginning from the ULF frequency band, through the VLF frequency band up to HF frequency band can be observed. Moreover, theoretical considerations indicated that the generation of those waves were induced even by some local drivers such as, for example, a beam of energetic particles, or by remote indicators located at the equator of the plasmapause. The investigation showed the main ionospheric trough region is a turbulent plasma region, particularly during geomagnetic disturbances. The plasma heating process starts at the plasmapause equator and this is followed by a transfer of heat along the field line to the topside ionosphere region and excites the turbulent region of the ionospheric plasma.

The existence of fossil broadband emission inside the plasmasphere close to the plasmapause after strong geomagnetic disturbances was also detected and analysed. This fact confirmed the previous observation of a turbulent plasma region located inside the plasmasphere close to the plasmapause but registered at a few Earth radii. The broadband electromagnetic and electrostatic fossil emissions observed in the VLF and HF frequency range after strong disturbances will now 
allow the construction of more realistic models of the energy transfer in the ionosphere-magnetosphere coupling processes. The new observation of physical phenomena occurring in the trough region registered the DEMETER satellite support the model constructed previously using the IK-19 and MAGION-3 satellites.

Furthermore, the data collected by the DEMETER satellite show that during an increasing level of geomagnetic activity an enhancement of Alfvén and EMIC waves inside the ionospheric trough region can be observed.

An improved model of trough features needs to be constructed on well-understood physical principles and phenomena occurring in the near-Earth environment rather than solely based on statistics. The above-described process registered in the main ionospheric analysis can be very helpful in understanding the ionosphere and inner magnetosphere physics. As long as there is no multi-scale or multi-point plasma ionospheric measurements, it seems necessary to examine previous data from low-orbiting spacecraft and measurements from dozens of ionospheric and GPS stations. This unique database, and such an approach to constructing models for Space Weather purposes, make it possible to update models according to different solar-geophysical circumstances.

Acknowledgements. Research partly supported by the Polish Committee of Scientific Research Grant No. 78/E-73SPB/COST/T12/DWM96/2004-2006 and No. COST/43/2007.

Topical Editor M. Pinnock thanks P. Bradley and two other anonymous referees for evaluating this paper.

\section{References}

Baran, L. W., Shagimuratov, I. I., and Tepenitsina, N. J.: The Use of GPS for Ionospheric Studies, Artificial Satellites, 32(1), 49-60, 1997.

Berthelier, J. J., Godefroy, M., Leblanc, F., Malingre, M., Menvielle, M., Lagoutte, D., Brochot, J. Y., Colin, F., Elie, F., Legendre, C., Zamora, P., Benoist, D., Chapuis, Y., and Artru, J.: ICE, The electric field experiment on DEMETER, Planet. Space Sci., 54(5), 456-471, 2006.

Blagoveshchensky D. V., Lester, M., Kornienko, V. A., Shagimuratov, I. I., Stocker, A. J., and Warrington, E. M.: Observations by the CUTLASS radar, HF Doppler, oblique ionospheric sounding, and TEC from GPS during a magnetic storm, Ann. Geophys., 23, 1697-1709, 2005, http://www.ann-geophys.net/23/1697/2005/.

Bradley, P. A., Juchnikowski, G., Rothkaehl, H., and Stanislawska, I.: Instantaneous maps of the European middle and High-latitude ionosphere for HF propagation assessments, Adv. Space Res., 22(6), 861-864, 1998.

Dudeney, J. R., Rodger, A. S., and Jarvis, M. J.: Radio studies of main ionospheric trough in Antarctica, Radio Sci., 18(6), 927936, 1983.

Evans, J. V., Holt, J. M., Oliver, W. L., and Wand, R. H.: The fossil Theory Of Nighttime High Latitude F Region Troughs, J. Geophys. Res., 88(A10), 7769-7782, 1983.
Foster, J. C., del Pozo, C., Groves, K., and St. Maurice, J.-P.: Radar Observations Of The Onset Of Current Driven Instabilites In The Topside Ionosphere, Geophys. Res. Lett., 15(2), 160-163, 1988.

Foster, J. C. and Vo, H. B.: Average characteristics and activity dependence of the subauroral polarization stream, J. Geophys. Res., 107(A12), 1475, doi:10.1029/2002JA009409, 2002.

Fraser, B. J. and Nguyen, T. S.: Is the plasmapause a preferred source region of electromagnetic ion cyclotron waves in the magnetosphere?, J. Atmos. Solar-Terr. Phys., 63, 1225-1247, 2001.

Fuller-Rowell, T. J., Rees, D., Quegan, S., and Moflett, R. J.: Numerical simulations of the sub-auroral F-region trough, J. Atmos. Terr. Phys., 53, 529-540, 1991.

Georgiadiou, J.: Modeling the Ionosphere for an Active Control Networks of GPS Stations, LGP Series, Publications of the Delft Geodetic Computing Centre, 7, 28p., 1994.

Gorbachev, O. A.: A theoretical model for the ring current interation with the Earth's plasmasphere, Planet. Space Sci., 40, 859872, 1992.

Grebowsky, J. M., Maynard, N. C., Tulunay, Y. K., and Lanzerotti, L. J.: Coincident observations of ionospheric troughs and the equatorial plasma-pause, Planet. Space Sci., 24, 1177-1185, 1976.

Hedin, M., Häggström, I., Pellinen-Wannberg, A., Andersson, L., Brändström, U., Gustavsson, B., Steen, Å., Westman, A., Wannberg, G., van Eyken, T., Aso, T., Cattell, C., Carlson, C. W., and Klumpar, D.: 3-D extent of the main ionospheric trough - a case study, Adv. Polar Upper Atmos. Res., 14, 157-162, 2000.

Jiricek, F., Šmilauer, J., Triska, P., and Trisková, L.: Response of the outer ionosphere to the magnetic storm of 20-22 March 1990, J. Atmos. Terr. Phys., 58(7), 855-865, 1996.

Karpatchev, A. T., Deminov, M. G., and Afonin, V. V.: Model Of The Mid-Latitude Ionospheric Trough On The Base Of COSMOS-900 And INTERCOSMOS-19 Sattelites Data, Adv. Space Res., 18(6), 221-230, 1996.

Karpatchev, A. T.: The dependence of main ionospheric trough shape on longitude, altitude, season, local time, and solar and magnetic activity, Geomag. Aeronomy, 43, 239-251, 2003.

Kazanov, G. V., Gombosi, T. I., Gorbachev, O. A., Trukhan, A. A., and Miller, R. H.: Thermodynamic Effect Of The Ion Sound Instability In The Ionosphere, J. Geophys. Res., 99(A4), 57215726, 1994.

Knudsen, W. C., Banks, P. M., Winningham, J. D., and Klumpar, D. M.: Numerical model of the convecting F2 ionosphere at high latitudes, J. Geophys. Res., 82, 4784-4793, 1977.

Krankowski, A., Shagimuratov, I. I., Baran, L. W., and Yakimova, G. A.: Storm-time changes of ionospheric TEC during the November 5, 2001 disturbances, Bulgarian Geophys. J., 30(1-4), 10-22, 2004.

Krankowski, A., Kosek, W., Baran, L. W., and Popiński, W.: Wavelet analysis and forecasting of VTEC obtained with GPS observations over European latitudes, J. Atmos. Solar-Terr. Phys., 67, 1147-1156, 2005a.

Krankowski, A., Shagimuratov, I. I., Baran, L. W., and Ephishov, I. I.: Study of TEC fluctuations in Antarctic ionosphere during storm using GPS observations, Acta Geophysica Polonica, 53(2), 205-218, 2005b.

Lanyi, G. E. and Roth, T.: A Comparison of Mapped and Measured Total Ionospheric Electron Content Using Global Positioning System and Beacon Satellite Observations, Radio Sci., 23(4), 
483-492, 1988.

Lebreton, J. P., Stverak, S., Travnicek, P., Maksimovic, M., Klinge, D., Merikallio, S., Lagoutte, D., Poirier, B., Kozacek, Z., and Salaquarda, M.: The ISL Langmuir Probe experiment and its data processing onboard DEMETER: scientific objectives, description and first results, Planet. Space Sci., 54(5), 472-486, 2006.

Lemaire, J. F.: The formation of the light-ion trough and peeling of the plasmasphere, J. Atmos. Solar-Terr. Phys., 63, 1285-1291, 2001.

Mendillo, M. and Chacko, C. C.: The baselevel ionospheric trough, J. Geophys. Res., 82(32), 5129-5137, 1977.

Moffett, R. J. and Quegan, S.: The mid-latitude trough in the electron concentration of the ionospheric F layer: a review of observations and modelling, J. Atmos. Terr. Phys., 45, 315-343, 1983.

Muldrew, D. B.: F-Layer Ionisation Trough Deducted From Alouette Data, J. Geophys. Res., 70(11), 2635-2650, 1965.

Nilsson, H., Sergienko, T.-I., Yamauchi, M., and Ebihara, Y.: Quiet time mid-latitude trough: influence of convection, field-aligned currents and proton precipitation, Ann. Geophys., 23, 32773288, 2005 ,

http://www.ann-geophys.net/23/3277/2005/.

Parrot, M.: The micro-satelitte DEMETER, J. Geodynamics, 33, 535-541, 2002.

Reynolds, M. A., Meléndez-Alvira, D. J., and Ganguli, G.: Equatorial coupling between the plasmasphere and the topside ionosphere, J. Atmos. Solar-Terr. Phys., 63, 1267-1273, 2001.

Rodger, A. S., Moffett, R. J., and Quegan, S.: The role of ion drift in the formation of the ionisation troughs in the mid- and highlatitude ionosphere - a review, J. Atmos. Terr. Phys., 54, 1-30, 1992.

Rothkaehl, H., Jiricek, F., Šmilauer, S., and Förster, M.: Dynamic Changes in the Outer Ionosphere in the Region of the Ionospheric Trough During an Intense Magnetic Storm, Adv. Space Res., 20/3, 409-414, 1997.

Rothkaehl, H., Stanisławska, I., Leitinger, R., and Tulunay, Y.: Application of the Trough Phenomena for telecommunication purposes, Phys. Chem. Earth, 25(4), 315-318, 2000.

Rycroft, M. J. and Burnell, S. J.: Statistical Analysis Of Movements Of The Ionospheric Trough And Plasmapause, J. Geophys. Res., 75(28), 5600-5604, 1970 .
Quegan, S., Bailey, G. J., Mofflett, R. J., Heelis, T. J., Fuller-Rowell, T. J., Rees, D., and Spiro, W.: A theoretical study of the distribution of ionisation in the high-latitude ionosphere and plasmasphere: first results on the mid-latitude trough and the light-ion trough, Atmos. Terr. Phys., 44, 619-640, 1982.

Sauvaud, J. A., Moreau, T., Maggiolo, R., Treilhou, J. P., Jacquey, C., Cros, A., Coutelier, J., Rouzaud, J., Penou, E., and Gangloff, M.: High energy electron detection onboard DEMETER: the IDP spectrometer, description and first results on the inner belt, Planet. Space Sci., 54(5), 502-511, 2006.

Smith, A. J., Rodger, A. S., and Thomas, D. W. P.: Simultaneous Ground-Based Observations Of The Plasmapause And The FRegion Mid-Latitude Trough, J. Atmos. Terr. Phys., 49, 43-47, 1987.

Sojka, J. J., Schunk, R. W., and Whalen, J. A.: The longitude Dependence of the Dayside F Region Trough: A Detailed ModelObservation Comparison, J. Geophys. Res., 95, 15 275-15 280, 1990.

Tulunay, Y. K.: Magnetically symmetrical detection of the midlatitude electron density trough by the Ariel-3 satellite, J. Atmos. Terr. Phys., 34, 1547-1551, 1972.

Tulunay, Y. K. and Grebowsky, J. M.: The noon and midnight midlatitude trough as seen by Ariel 4, J. Atmos. Terr. Phys., 40, 845855, 1978.

Tulunay, Y., Stanisawska, I., and Rothkaehl, H.: Revisiting the Ariel Trough Work for HF Telecommunication Purposes, Cosmic Res., 41(4), 319-331, 2003.

Vo, H. B. and Foster, J. C.: A quantative study of ionospheric density gradients at midlatitudes, J. Geophys. Res., 106(A10), 21 555-21 563, 2001.

Werner, S. and Proelss, G. W.: The position of the Ionospheric Trough as a function of local time and magnetic activity, Adv. Space Res., 20(9), 1717-1722, 1997.

Yizengaw, E. and Moldwin, M. B.: The altitude extension of the mid-latitude trough and its correlation with plasmapause position, Geophys. Res. Lett., 32, L09105, doi:10.1029/2005GL022854, 2005. 